\title{
Mechanical Ventilation of the Premature Neonate
}

\author{
Melissa K Brown RRT-NPS and Robert M DiBlasi RRT-NPS FAARC
}

\author{
Introduction \\ Patient-Triggered Ventilation \\ Continuous Mandatory Ventilation and Synchronized Intermittent \\ Mandatory Ventilation \\ Pressure Support Ventilation \\ Neurally Adjusted Ventilatory Assist \\ Pressure Control Ventilation Versus Volume-Targeted Ventilation \\ Lung-Protective Strategies \\ High-Frequency Ventilation \\ Closed-Loop $\mathrm{F}_{\mathrm{IO}_{2}}$ Control \\ Summary
}

\begin{abstract}
Although the trend in the neonatal intensive care unit is to use noninvasive ventilation whenever possible, invasive ventilation is still often necessary for supporting pre-term neonates with lung disease. Many different ventilation modes and ventilation strategies are available to assist with the optimization of mechanical ventilation and prevention of ventilator-induced lung injury. Patient-triggered ventilation is favored over machine-triggered forms of invasive ventilation for improving gas exchange and patient-ventilator interaction. However, no studies have shown that patient-triggered ventilation improves mortality or morbidity in premature neonates. A promising new form of patient-triggered ventilation, neurally adjusted ventilatory assist (NAVA), was recently FDA approved for invasive and noninvasive ventilation. Clinical trials are underway to evaluate outcomes in neonates who receive NAVA. New evidence suggests that volume-targeted ventilation modes (ie, volume control or pressure control with adaptive targeting) may provide better lung protection than traditional pressure control modes. Several volume-targeted modes that provide accurate tidal volume delivery in the face of a large endotracheal tube leak were recently introduced to the clinical setting. There is ongoing debate about whether neonates should be managed invasively with high-frequency ventilation or conventional ventilation at birth. The majority of clinical trials performed to date have compared high-frequency ventilation to pressure control modes. Future trials with premature neonates should compare high-frequency ventilation to conventional ventilation with volumetargeted modes. Over the last decade many new promising approaches to lung-protective ventilation have evolved. The key to protecting the neonatal lung during mechanical ventilation is optimizing lung volume and limiting excessive lung expansion, by applying appropriate PEEP and using shorter inspiratory time, smaller tidal volume $(4-6 \mathrm{~mL} / \mathrm{kg})$, and permissive hypercapnia. This paper reviews new and established neonatal ventilation modes and strategies and evaluates their impact on neonatal outcomes. Key words: neonatal; infant; mechanical ventilation; intensive care; noninvasive ventilation; ventilator-induced lung injury; neurally adjusted ventilatory assist; high-frequency ventilation. [Respir Care 2011;56(9):1298-1311. () 2011 Daedalus Enterprises]
\end{abstract}




\section{Introduction}

Since its inception, the neonatal mechanical ventilator has been considered an essential tool for managing premature neonates with respiratory distress syndrome (RDS) and is still regarded as an integral component in the neonatal respiratory care continuum. Prior to the early 1970s, neonates either died without access to appropriate ventilators, or they were supported in the first days of life with pediatric volume ventilators and a large pre-set tidal volume $\left(\mathrm{V}_{\mathrm{T}}\right)$ (approximately $18 \mathrm{~mL} / \mathrm{kg}$ ). Fast set respiratory rates and PEEP were believed to increase barotrauma and thus were not used. The ongoing clinical management was based principally on subjective assessment of optimal chest rise, breath sounds, color, and maintaining normal blood gas values.

Infant mortality caused by RDS in the United States decreased from approximately 268 in 100,000 live births in 1971 to 98 in 100,000 live births in $1985^{1}$ to 17 in 100,000 live births in $2007 .^{2}$ The mortality decrease from 1971 to 1985 was no doubt multi-factorial, but improvements in ventilator technology and the training and experience of respiratory therapists certainly played an important role.

In the last decade the role of mechanical ventilation in the neonatal intensive care unit (NICU) has been evolving. Invasive mechanical ventilation, although often necessary for supporting neonates with lung disease, has been implicated as a major cause of lung injury and inflammation, and is now considered a primary risk factor for neonates developing bronchopulmonary dysplasia (BPD). ${ }^{3,4}$ As such, institutions with better outcomes appear to be taking a different approach to mechanical ventilation. Assuming a neonate has an acceptable respiratory effort, even the smallest and youngest of these patients are now being supported

\footnotetext{
Ms Brown is affiliated with the Respiratory Therapy Program, Grossmont Community College, El Cajon, California, and with the Chest Medicine and Critical Care Medical Group, Sharp Memorial Hospital, San Diego, California. Mr DiBlasi is affiliated with the Center for Developmental Therapeutics, Seattle Children's Research Institute, and with the Department of Respiratory Care, Seattle Children's Hospital and Research Institute, Seattle, Washington.
}

Ms Brown presented a version of this paper at the 47th RESPIRATORY CARE Journal Conference, "Neonatal and Pediatric Respiratory Care: What Does the Future Hold?" held November 5-7, 2010, in Scottsdale, Arizona.

Ms Brown has disclosed no conflicts of interest. Mr DiBlasi has disclosed relationships with Monaghan Medical and GE Healthcare.

Correspondence: Melissa Brown RRT-NPS, Respiratory Therapy Program, Grossmont Community College, 8800 Grossmont College Drive, El Cajon CA 92020. E-mail: melissa.brown@sharp.com.

DOI: $10.4187 /$ respcare. 01429 noninvasively using gentler forms of mechanical respiratory support (eg, continuous positive airway pressure). Even when invasive ventilation is required, strategies are now more focused than ever on how quickly patients can be liberated from invasive support.

Although increasingly smaller infants are being sustained successfully without invasive support, there continues to be an important place for invasive ventilation. In a recent randomized controlled trial (RCT), investigators from the SUPPORT (Study to Understand Prognoses and Preferences for Outcomes and Risks of Treatment) trial ${ }^{5}$ reported that $35 \%$ of the $24-28$-week gestational-age neonates who were randomized to the continuous-positiveairway-pressure arm required invasive ventilation in the delivery room, and $83 \%$ required invasive ventilation at some point during the trial. The major causes for premature neonates requiring invasive support are poor gas exchange, increased work of breathing (WOB), apnea of prematurity, and/or the need for surfactant-replacement therapy.

Nearly 3 decades following the advent of the microprocessor, several advances in neonatal ventilator technology have ushered in a number of proposed improvements to the neonatal ventilator. These include patient-triggered ventilation, $\mathrm{V}_{\mathrm{T}}$ monitoring at the proximal airway, and new ventilation modes. While a tremendous amount of resources have gone into the design and testing of these devices, the question remaining is, have these advances actually improved outcomes for neonates? While it would seem natural that the answer is probably yes, the technology has advanced so quickly that it is not surprising that no single RCT has demonstrated differences in mortality and morbidity related to the use of newer ventilator technologies. Major reasons for this include:

- Neonatal patients are difficult to enroll into clinical trials.

- A very large number of patients is needed to find subtle differences in morbidity and mortality.

- Many manufacturers are unwilling or unable to support expensive studies.

- Ventilator software tends to change so frequently that it is difficult for research to keep up with the technology changes.

Improvements to neonatal ventilators have not come without a cost. Current-generation ventilators have added a new level of complexity and expense to neonatal care. It is not uncommon for clinicians to be seduced by new advanced features found on neonatal ventilators. However, increased complexity of technology may increase risk to patients. These risks include misunderstanding and misapplication by clinicians. But in reality many of these fea- 

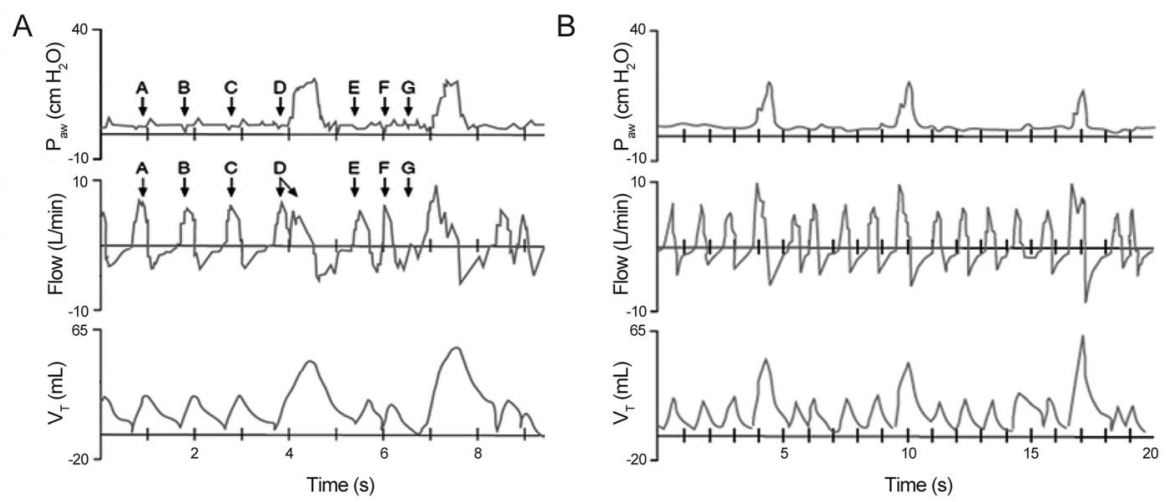

Fig. 1. A: Machine-triggered intermittent mandatory ventilation (IMV) with inadequate patient triggering of mandatory breaths. The patient is receiving pressure-controlled, time-cycled, continuous-flow IMV. Points A-C are unassisted spontaneous breaths. At point D the patient begins to exhale, but before exhalation begins, a positive pressure breath is delivered, resulting in breath-stacking and patient-ventilator asynchrony. B: Synchronized intermittent mandatory ventilation. All of the mandatory breaths are patient-triggered and delivered appropriately by the ventilator. (Adapted from Reference 6, with permission.)

tures are never used in clinical practice. Thus, the seasoned clinician is left wondering if the costs and risks of novel ventilators and ventilation modes outweigh the clinical benefit to patients. This paper will address many of the past and recent advances in neonatal ventilators and management strategies, review outcomes data related to these advances, and explore some of the more promising approaches to neonatal ventilation that are on the horizon.

\section{Patient-Triggered Ventilation}

Early neonatal pressure ventilators were relatively inexpensive and simple to operate. There was typically only one mode to set on these ventilators. Mechanical breaths were machine-triggered, time-cycled, and pressurecontrolled. Intermittent mandatory ventilation (IMV) provided intermittent pressure-controlled breaths. and unassisted spontaneous breathing occurred in between the scheduled ventilator breaths. A pre-set continuous flow provided blended gas delivery for spontaneous breaths and mechanical breaths alike. There was great potential for mechanical breaths to be delivered out of phase with the neonate's spontaneous respiratory effort, resulting in the patient fighting the ventilator (Fig. 1A). ${ }^{6}$ Because the ventilator essentially functioned independent of the patient, poor patient-ventilator interaction could lead to inadequate gas exchange, air leaks, gas trapping, and increased ventilator support. ${ }^{7}$ To improve patient-ventilator synchrony and patient comfort and to prevent some of these complications during IMV, neonates were heavily sedated and or neuromuscularly paralyzed or hyperventilated with the ventilator. $^{8}$

Patient-triggered ventilation became the standard in adult mechanical ventilators prior to being adopted in the NICU. The theoretical advantages of allowing small patients the ability to initiate mandatory ventilator breaths based on their own intrinsic respiratory efforts during patient-triggered ventilation include:

- Lower and more consistent ventilator pressure and less fluctuation in intracranial pressure

- Increased patient comfort with less sedation, which may facilitate ventilator weaning

- Less gas trapping and fewer air leaks

- Improved oxygenation and ventilation ${ }^{7}$

The reason for the slow acceptance of patient-triggered ventilation in the NICU is primarily the technical limitations involved in detecting and responding rapidly to small patient efforts. Respiratory monitoring during ventilation has grown more comprehensive and sophisticated. Today most neonatal ventilators incorporate small, lightweight, hot-wire or variable orifice flow sensors that can accurately and precisely measure flow and pressure changes at the proximal airway and provide patient-triggered ventilation in even the smallest of patients. Once the ventilator senses a patient effort based on these changes, a signal is sent to the flow-control valve, the valve opens, and the breath is initiated. Flow-triggering with a sensor placed at the proximal airway (Fig. 2) is currently preferred over pressure-triggering. ${ }^{910}$ A proximal flow sensor has become necessary not only for triggering, but for accurate $\mathrm{V}_{\mathrm{T}}$ measurement and airway graphic display. ${ }^{9-11}$ Table 1 shows the advantages and disadvantages of the available neonatal ventilator triggering methods.

The limitations of flow sensors include extra weight on the ETT, more mechanical dead space, and that sensor reliability can be compromised by accumulated secretions in the sensor. Thus, some centers are reluctant to use prox- 


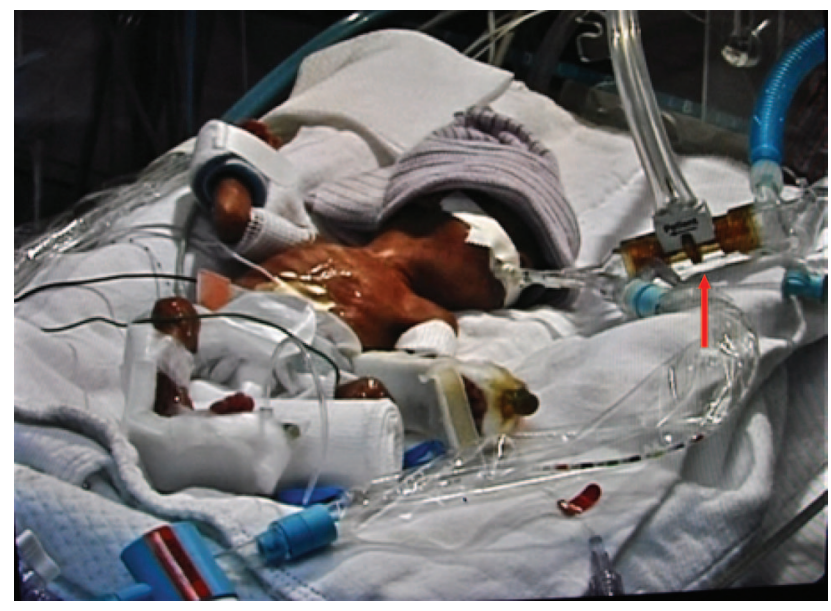

Fig. 2. Neonatal flow sensor, at the airway, between the ventilator circuit and the endotracheal tube adapter (arrow).

imal flow sensing and therefore rely on flow and pressure measurements not made at the proximal airway. In a study to determine the impact of mechanical dead space from a proximal flow sensor, Nassabeh-Montazami concluded that while there is a measurable effect on the tiniest infants, the value of accurate $\mathrm{V}_{T}$ measurements and synchronization, outweigh any small attendant risk. ${ }^{12}$

In the NICU there is also the additional difficulty of dealing with ETTs that are un-cuffed, which causes large positional air leaks around the ETT, which can lead to auto-triggering and missed triggers. Some ventilator manufacturers have dealt with this problem by building sophisticated leak compensation algorithms. When this option is activated, loss of end-expiratory pressure caused by an ETT leak triggers the addition of flow to the ventilator circuit to maintain constant PEEP, which decreases the likelihood of inappropriate triggering.

\section{Continuous Mandatory Ventilation and Synchronized Intermittent Mandatory Ventilation}

The most widely used forms of patient-triggered ventilation in the NICU are what have been referred to as "assist/control" and "synchronized intermittent mandatory ventilation" (SIMV). Unfortunately, these are specific names of modes found on some but not all ventilators. When reviewing the literature covering many different ventilators and many different author preferences for nomenclature, we need to talk in terms of tags or general classes of modes, not specific names. Furthermore, in the pediatric literature these terms are understood to be forms of pressure control, whereas in the adult literature they are understood to be forms of volume control.

In this paper we will use the general mode classification of pressure control continuous mandatory ventilation (PCCMV) to mean any mode where inspiratory pressure is pre-set and every breath is mandatory (ie, machine-triggered and/or machine-cycled). We will use the term pressure control intermittent mandatory ventilation (PC-IMV) to mean any mode where inspiratory pressure is pre-set and spontaneous breaths (breaths that are both triggered and cycled by the patient) may occur between mandatory breaths. A peculiarity of the pediatric literature is the emphasis on the distinction between PC-IMV (in which all mandatory breaths are machine triggered, which we will refer to as PC-IMV) (Fig. 1A) and PC-IMV (in which mandatory breaths may be patient triggered), which we will refer to as PC-SIMV (Fig. 1B). These forms of patient-triggered ventilation are preferred because premature neonates often have unpredictable breathing patterns, and as long as the ventilator rate is set high enough, then there is sufficient machine-triggered backup breaths to support neonates who develop periodic breathing or apnea.

Several small studies have evaluated differences in shortterm physiologic outcomes between PC-SIMV and PCIMV in premature neonates. Table 2 lists some of the observed clinical benefits of PC-SIMV over PC-IMV. ${ }^{13-16}$ There have also been several small short-term clinical trials of PC-SIMV versus PC-IMV or PC-CMV versus PCIMV. ${ }^{13-20}$ Overall, in neonates, PC-CMV has shown less $\mathrm{V}_{\mathrm{T}}$ variability, shorter weaning time, lower $\mathrm{WOB}$, and better blood gas values and vital signs than PC-SIMV, and lower WOB and shorter duration of weaning than PCIMV. ${ }^{15}$

A recent Cochrane meta-analysis ${ }^{21}$ evaluated 14 RCTs and compared differences in outcomes with patient-triggered ventilation versus non-patient-triggered ventilation (eg, PC-IMV). Compared to non-patient-triggered breath types, premature neonates supported with patient-triggered ventilation (PC-CMV or PC-SIMV) had shorter duration of ventilation (weighted mean difference $-34.8 \mathrm{~h}$, 95\% CI -62.1 to -7.4 ). Compared to PC-SIMV, PC$\mathrm{CMV}$ was associated with a nonsignificant trend toward shorter duration of weaning (weighted mean difference -42.4 h, $95 \%$ CI -94.4 to 9.6). There were no significant differences in mortality or morbidity related to trigger method. Clearly patient-triggered ventilation modes provide some short-term benefits over non-patient-triggered modes, but many of the ventilators used in those studies were earlier-generation microprocessor controlled neonatal ventilators. It is unclear if the recent enhancements in patient-triggered ventilation in current ventilators offer better synchronization and outcomes in neonates than those tested in those earlier studies.

\section{Pressure Support Ventilation}

Pressure support ventilation (PSV) is a form of patienttriggered ventilation that is becoming more commonly used in the NICU for weaning or as an auxiliary breath type 


\section{Mechanical Ventilation of the Premature Neonate}

Table 1. Advantages and Disadvantages of Available Neonatal Ventilator Triggering Methods

\begin{tabular}{lll}
\hline \hline \multicolumn{1}{c}{ Triggering Method } & \multicolumn{1}{c}{ Advantages } & \multicolumn{1}{c}{ Disadvantages } \\
\hline Flow & Quick response time, highly sensitive, noninvasive & Affected by leaks, added dead space and weight \\
Pressure & No added dead space or weight, noninvasive & Longer trigger delay, lower sensitivity \\
$\begin{array}{l}\text { Diaphragm electromyogram (neurally } \\
\text { adjusted ventilatory assist) }\end{array}$ & $\begin{array}{l}\text { Fastest response time, not affected by leaks, } \\
\text { highly sensitive }\end{array}$ & $\begin{array}{c}\text { Probe positioning more difficult, probe cost, } \\
\text { invasive }\end{array}$
\end{tabular}

(Adapted from Reference 11.)

Table 2. Early Studies of Patient-Triggered Ventilation in Premature Neonates

\begin{tabular}{lll}
\hline \hline First Author, year & Ventilation Modes & Short-term outcomes \\
\hline Bernstein, 1994 & PC-IMV vs PC-SIMV & $\begin{array}{c}\text { PC-SIMV provided larger }(P<0.01) \text {, more consistent }(P<.001) \text { tidal volumes than } \\
\text { PC-IMV in neonates } \\
\text { Cleary, 1995 }\end{array}$ \\
& PC-IMV vs PC-SIMV & $\begin{array}{c}\text { PC-SIMV provided greater oxygenation }(P<0.01) \text { and ventilation }(P<.05) \text { than } \\
\text { PC-IMV in neonates }\end{array}$ \\
Jarreau, 1996 & PC-IMV vs PC-SIMV & PC-SIMV provided lower work of breathing than PC-IMV $(P<.05)$ in neonates \\
Smith, $1997^{16}$ & PC-IMV vs PC-SIMV & PC-SIMV provided lower respiratory rate than PC-IMV $(P<.01)$ in neonates
\end{tabular}

PC-IMV = pressure controlled intermittent mandatory ventilation

PC-SIMV $=$ pressure controlled synchronized intermittent mandatory ventilation

Adapted from Reference 11

used in conjunction with SIMV. PSV is classified as a form of pressure control continuous spontaneous ventilation, but because it appears on just about all ventilators, we will use the term PSV instead of the lesser-known term pressure control continuous spontaneous ventilation, to avoid confusion. PSV differs from PC-CMV in that every breath is patient triggered and cycled (by means of a flowcycle criterion). In PSV the patient controls the start of inspiration, the start of expiration, the inspiratory time, the breathing frequency, and the minute volume, so the patient has complete control of the breath, which enhances patient comfort and patient-ventilator synchrony. ${ }^{22}$ It is important to note that to use PSV the neonate must have sufficient respiratory drive. While newer PSV modes have an apnea backup mode, it takes time for the ventilator to sense apnea before mandatory backup breaths are delivered. Patients with persistent and frequent apnea may be better served by PC-CMV or PC-SIMV. A large ETT leak can also pose a problem for PSV, because the leak may not allow the patient to flow-cycle to exhalation. Most ventilators have added secondary time-cycling criteria to provide appropriate breath-termination when flow-cycling cannot be achieved during PSV.

Pre-term neonates use frequent sighs to recruit and maintain end-expiratory lung volume and maintain oxygenation. ${ }^{23}$ It has been speculated that PSV may better enable a ventilated neonate to establish a breathing pattern that includes sighs. ${ }^{24}$ PSV may be particularly useful in patients who are difficult to manage with a fixed inspiratory time and respiratory rate (eg, PC-CMV). This is especially true in infants with high airway resistance (ie, chronic lung disease), who are prone to developing gas trapping. In a case report, Nicks et al ${ }^{25}$ observed lower airway pressure and improved $\mathrm{V}_{\mathrm{T}}$ and compliance when a neonate with BPD was transitioned from PC-SIMV to PSV. This resulted in the ability to promptly wean and extubate the patient from mechanical ventilation.

PSV has evolved to employ adaptive targeting: for example, "volume support" (on the Servo-i ventilator, Maquet, Solna, Sweden) or "pressure support volume guarantee" (on the VN500, Dräger, Lübeck, Germany), which is a mode that automatically adjusts the inspiratory pressure to maintain a minimum pre-set $\mathrm{V}_{\mathrm{T}}$ target. Nafday et $\mathrm{al},{ }^{26}$ in a small, unblinded RCT with 34 premature neonates with RDS, compared pressure support volume guarantee to PC-SIMV as the initial ventilation mode after surfactant-replacement therapy. There was a faster reduction in mean airway pressure in the PC-SIMV group, and only a reduced need for arterial blood gas analysis in the pressure-support-volume-guarantee group, which is probably related to better control and maintenance of the $\mathrm{V}_{\mathrm{T}}$. Olsen et $\mathrm{al}^{27}$ investigated short-term clinical effects of pressure support volume guarantee versus PC-SIMV in a crossover trial with 14 pre-term neonates recovering from RDS. The pressure-support-volume-guarantee group had higher respiratory rate, larger minute ventilation, and lower end-expiratory lung volume, and required higher mean airway pressure. Olsen et al speculated that deterioration in lung recruitment was partly due to shorter inspiratory time during pressure support volume guarantee. 
PSV is now becoming a common supplemental mode in patients supported with PC-SIMV. The addition of PSV during PC-SIMV may aid in overcoming the resistance of a small ETT during intermittent spontaneous breaths. Gupta et $\mathrm{al}^{28}$ observed greater increase in minute ventilation and a concomitant reduction in patient respiratory rate in neonates supported with PC-SIMV with pressure support, versus PC-SIMV without pressure support. Reyes et $\mathrm{al}^{29}$ conducted an RCT with 107 premature neonates with RDS, allocated to PC-SIMV either with or without pressure support, for $28 \mathrm{~d}$. The neonates who received pressure support reached minimal ventilator settings and were extubated sooner than the PC-SIMV-only group. The pressure-support subgroup of infants who weight $700-1,000 \mathrm{~g}$ had a shorter exposure to supplemental oxygen, but also received more surfactant. However, there were no differences in mortality or BPD between the 2 treatment groups.

Most new neonatal ventilators allow the clinician the option to switch from time-cycled mandatory breaths to flow-cycled breaths during PC-SIMV or PC-CMV. This form of ventilation is known in the neonatal ventilation arena as "flow-cycled ventilation." Once the patient is on flow-cycled ventilation, mandatory breaths become spontaneous PSV breaths, but at a higher inspiratory pressure than would typically be used during PSV. The inspiratory requirements of premature neonates can vary considerably with changes in the pathophysiology. Some clinicians enable flow-cycled ventilation for a short period, to observe the patient's inspiratory time while observing $\mathrm{V}_{\mathrm{T}}$ and $\mathrm{WOB}$, and then place the patient back on time-cycled ventilation at a different inspiratory time. That procedure is known as inspiratory time assessment. Many ventilators do not advise the clinician when flow-cycling is turned on, and the clinician may think that the breaths are still being timecycled. This could pose a problem if a large leak develops or if lung mechanics deteriorate, so flow-cycled ventilation should be used with extreme caution, as it may reduce mean airway pressure and lung inflation, especially if the patient is not being monitored appropriately.

A recent meta-analysis assessed the effect of flow-cycled versus time-cycled patient-triggered ventilation (ie, PSV vs PC-CMV and PC-SIMV) on outcomes in premature neonates. ${ }^{24}$ Unfortunately, only 2 small randomized short-term crossover trials were eligible, and they reported on only lung mechanics and short-term physiologic outcomes. There was not enough evidence to support the use of flow-cycled ventilation over traditional time-cycled ventilation.

Few studies have addressed clinical outcomes of the wide variety of available patient-triggered ventilation approaches in premature neonates. Kapasi et al ${ }^{30}$ evaluated WOB and other indices of patient-ventilator synchrony during PC-IMV, PC-SIMV, PC-CMV, and PSV in 7 premature neonates. The patient-triggered modes all resulted

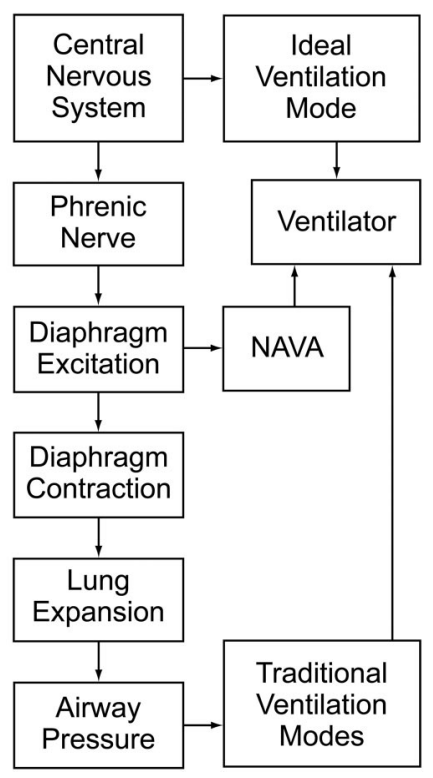

Fig. 3. Neurally adjusted ventilatory assist (NAVA) ventilation is triggered by the electrical activity of the diaphragm. Traditional ventilation modes are triggered by airway pressure or flow. (Adapted from Reference 31 and 32.)

in better patient-ventilator synchrony and less WOB than PC-IMV. Marked asynchrony occurred only during PCIMV, and PC-CMV had the worst asynchrony. PSV resulted in less patient effort and WOB than PC-IMV and PC-SIMV, but not PC-CMV.

Patient-triggered ventilation appears to hold clear advantages over traditional PC-IMV by improving patientventilator interaction and reducing time on the ventilator. PSV can assist with the WOB involved with spontaneous breathing and may also decrease the time spent on the ventilator when combined with PC-SIMV. However, PSV as a stand-alone mode, even when combined with a volume guarantee, may have a propensity to place the patient at greater risk of developing atelectasis. Unfortunately, there is not enough evidence to clearly recommend one particular mode over another at this time.

\section{Neurally Adjusted Ventilatory Assist}

Nasal neurally adjusted ventilatory assist (NAVA) is a novel form of noninvasive ventilation (NIV) in premature neonates. NAVA uses the electrical activity of the diaphragm (EAdi) to determine the timing and magnitude of inspiratory pressure delivery during spontaneous breathing (Fig. 3). ${ }^{31}$ The EAdi signal is obtained with a 5.5 French esophageal catheter with 10 electrodes. The catheter is placed so the electrodes are at the level of the diaphragm. ${ }^{32,33}$ When positioned properly, the EAdi signal can accurately and reliably trigger and cycle a positive-pressure breath, independent of air leak. Additionally, the magnitude of the 
inspiratory pressure assist is a product of the EAdi signal and the pre-set NAVA level. ${ }^{33}$ NAVA has been available as an invasive mode on the Servo i ventilator for nearly 2 years, and was recently FDA approved for NIV.

Beck et al ${ }^{33}$ studied 7 premature neonates (25-29 weeks gestational age) with resolving lung disease and who were ready to be extubated. In the first phase of the study, a NAVA catheter was placed, and airway pressure and EAdi were measured during a $60-$ min period on a conventional ventilator. The neonates were then placed on invasive NAVA at a level that provided airway pressure similar to that of conventional ventilation. Following a short period of NAVA, the neonates were extubated and supported with NAVA via a single nasal prong and at NAVA level similar to that at which they were extubated. No PEEP was used because of excessive leak during NAVA. NAVA resulted in lower mean airway pressure $(P=.002)$ and a higher oxygen requirement $(P=.003)$ than did the other testing conditions, due to poor pressure transmission from the leak. Interestingly, NAVA (without PEEP) resulted in a lower neural respiratory rate $(P=.004)$, less breathcycling delay, and better correlation between EAdi and airway pressure $(P<.001)$ than did invasive ventilation. This short-term study identified NAVA as a reasonable way to support spontaneously breathing premature neonates following, and potentially prior to, intubation.

Breatnach et $\mathrm{al}^{34}$ compared NAVA to PSV in 16 ventilated infants and children (age range $2 \mathrm{~d}$ to 4 years, mean 9.7 months, weight range $2.4-13.7 \mathrm{~kg}$, mean $6.2 \mathrm{~kg}$ ). NAVA improved patient-ventilator synchrony and lowered the peak inspiratory pressure, compared to PSV. The current data on NAVA are preliminary, but the initial studies appear to be positive, especially in terms of improved ventilator-patient synchrony. NAVA does seem to have the ability to trigger and cycle breaths during NIV, even in the presence of large leaks.

NAVA requires that the patient is breathing spontaneously. Premature neonates who are apneic may not be able to be supported by NAVA, even with a backup ventilation mode. In the study by Beck et al, ${ }^{33}$ premature neonates were supported with a prototype Servo 300 ventilator (Maquet, Solna Sweden), and NAVA is now commercially available only on the Servo-i ventilator. NAVA is invasive, relatively expensive, and requires frequent bedside attendance. Future studies with larger numbers of neonates are needed to assess outcomes with NAVA as a standard NIV approach for neonates with lung disease. There is also concern about the cost of the NAVA esophageal catheters, their proper placement, and their propensity to be accidentally dislodged, especially in the NICU population of small infants. Although many of the difficulties associated with flow sensors at the airway might be bypassed with this new EAdi method, new issues such as proper sensor placement and higher cost might develop instead.

\section{Pressure Control Ventilation Versus Volume-Targeted Ventilation}

Initial attempts at ventilating pre-term infants with volume ventilators were often unsuccessful and were quickly abandoned with the introduction of neonatal pressure ventilators. Today pressure control ventilation is widely used in neonates. Aside from being able to trigger pressure control breaths based on changes in flow or pressure, pressure control may offer some other subtle but clinically important differences. Historically, infant ventilators generated inspiratory pressure by directing a pre-set continuous flow through a pressure-relief valve. Depending on how the flow was set, inspiratory flow could be almost anything from constant flow (essentially volume control) with a triangular pressure waveform, to an exponential decay with a sharply rectangular pressure waveform. Current ventilators used with infants use sophisticated pressure control systems to generate either a rectangular pressure waveform or one that has a variable pressure rise. The unifying feature between the old and new ventilators is that with a rectangular pressure waveform, inspiratory flow is dependent on patient mechanics, including inspiratory demand.

Variable flow during pressure control is useful because patient flow demand is often variable and flow from the demand valve is delivered in response to large airway leaks and during active patient efforts to maintain inspiratory pressure constant. While intra-breath flow response is sufficient in the majority of patients, some neonates may require more aggressive gas delivery during pressure control. Some ventilators can provide a pre-set continuous flow as an alternative to variable flow during pressure control, and some patients may be more comfortable on continuous flow because higher flow may be available at the onset of patient inspiration. ${ }^{35}$

Since pressure is constant during pressure control, the $\mathrm{V}_{\mathrm{T}}$ delivery can vary with changes in lung mechanics and respiratory effort, which can cause rapid and large changes in $\mathrm{V}_{\mathrm{T}}$ (eg, after surfactant-replacement therapy) if the inspiratory pressure setting is not immediately weaned. Excessive $V_{T}$ increases the risk of ventilator-induced lung injury (VILI) and profound hypocarbia. There is compelling evidence that short-term exposure to volutrauma during mechanical ventilation initiates lung inflammation in premature infants, even after only a few minutes of manual resuscitation. ${ }^{36}$

Ventilation for $15 \mathrm{~min}$ with a $\mathrm{V}_{\mathrm{T}}$ of $15 \mathrm{~mL} / \mathrm{kg}$ injures the pre-term lung. ${ }^{36}$ As few as 3 over-distending breaths at birth compromised the therapeutic effect of subsequent surfactant replacement in an animal model of prematurity. ${ }^{36}$ Hyperventilation and the consequent hypocarbia can cause long-term neurological sequelae, cystic brain lesion, and periventricular leukomalacia. ${ }^{37,38}$ Conversely, 
if the pressure control level is not increased due to worsening lung mechanics and consequent hypoventilation, then the patient can become profoundly hypercarbic, which may increase the risk of developing intraventricular hemorrhage. ${ }^{39,40}$ Prolonged ventilation at low inspiratory pressure and low lung volume can also cause atelectrauma and VILI. ${ }^{41}$ Recently improved volume monitoring capabilities, lung mechanics measurements, and system alarms can better guide clinicians in ventilator adjustments.

The term "volume-targeted ventilation" is commonly used in the neonatal ventilation literature to describe breath types that achieve a minimum $\mathrm{V}_{\mathrm{T}}$ by using either volume control or adaptive pressure control (also known as dualcontrol). The concept of volume-targeted ventilation is not new, but its progression has been hampered by technological limitations of ventilators, preventing its application in infants. Improvements in signal processing, servo control, and volume monitoring have made volume- targeted ventilation a reality for even the smallest of patients. Most of the currently available neonatal-capable ventilators allow setting the $\mathrm{V}_{\mathrm{T}}$ as low as $2-3 \mathrm{~mL}$ and, remarkably, with great precision and accuracy. Sinha and colleagues first introduced this clinical approach in a RCT of volume control versus pressure control (targeted at $5-8 \mathrm{~mL} / \mathrm{kg}$ ) as an initial management strategy in pre-term neonates with RDS. ${ }^{42}$ The volume-control group had a significantly shorter duration of ventilation $(P<.001)$ and a trend toward a lower incidence for BPD $(P=.09)$ than the pressure-control group.

Adaptive pressure control involves volume-targeted breaths that automatically adjust inspiratory pressure based on $\mathrm{V}_{\mathrm{T}}$ measurements to target a minimum inspiratory or expiratory $\mathrm{V}_{\mathrm{T}}$. The $\mathrm{V}_{\mathrm{T}}$ measurements are obtained, during inhalation or exhalation, by a flow sensor at the patient Y-piece or at the ventilator exhalation valve.

A 2010 Cochrane review ${ }^{43}$ of 12 RCTs, including 9 parallel trials (with 629 infants) and 3 crossover trials (with 64 infants), compared volume-targeted ventilation to pressure control during mechanical ventilation. The volumetargeted modes reduced the combined outcome of death or chronic lung disease (risk ratio [RR] $0.73,95 \%$ CI 0.57 to 0.93 , NNT [number needed to treat] 8, 95\% CI 5 to 33), pneumothorax (RR $0.46,95 \%$ CI 0.25 to 0.84 , NNT 17 , 95\% CI 10 to 100), ventilation days (mean difference $-2.36 \mathrm{~d}, 95 \% \mathrm{CI}-3.9$ to -0.8 ), hypocarbia (typical RR $0.56,95 \%$ CI 0.33 to 0.96 ), NNT $4,95 \%$ CI 2 to 25 ), and the combined outcome of periventricular leukomalacia or grade 3-4 intraventricular hemorrhage (typical RR $0.48,95 \%$ CI 0.28 to 0.84 , NNT $11,95 \%$ CI 7 to $50)$. The neonates were supported with various volumetargeted ventilation modes, including volume control and adaptive pressure control modes. The major ques- tion is whether one mode performs better than another when considering the ability to maintain $\mathrm{V}_{\mathrm{T}}$ in the face of large leaks and with changes in lung mechanics and respiratory effort.

In a recent survey by the NeoVent group, NICUs in 21 European countries responded regarding 535 pre-term neonates. ${ }^{44}$ The respondents ventilated pre-term neonates with conventional ventilation $85 \%$ of the time, and with highfrequency ventilation (HFV) $15 \%$ of the time. During conventional ventilation the preferred mode was patient-triggered pressure control (79\%), and $\mathrm{V}_{\mathrm{T}}$ was monitored almost exclusively at the proximal airway. Only $11 \%$ of the respondents used modes that use a volume-targeted strategy, including volume control or adaptive pressure control. In the United States there have been no surveys designed to assess the prevalent ventilation modes used for neonates, but based on anecdotal reports it is likely that they are similar to those practiced in Europe. Based on the recent Cochrane review ${ }^{43}$ it is unclear why more clinicians are not choosing volume-targeted over pressure control strategies in neonates as an initial form of support for conventional ventilation. One notion may be that previous attempts at neonatal volume-targeted ventilation were made with adult and pediatric volume-cycled ventilators, during the mid-1970s, and those approaches often caused severe BPD or death. Another likely reason is that some of volume-targeted modes are cumbersome to operate and thus cause clinicians to resort to pressure control. The accuracy and precision of delivered $\mathrm{V}_{\mathrm{T}}$ with this method remains controversial in smaller infants, especially if the lung compliance is less than that of the ventilator circuit. ${ }^{45,46}$ It must be noted that all measurements, irrespective of source, are affected by ETT leaks, humidification, ventilator circuit compliance, and airway secretions. Some centers remove patients from volume-targeted ventilation if the ETT leak is $>30 \%$ or re-intubate with a larger ETT to eliminate the leak, so a volume-targeted mode can be used. It is unclear what the best practice is and whether the risks of reintubation with a larger ETT outweigh the benefits of implementing these modes.

Adaptive pressure control modes appear to show great promise for volume-targeted ventilation in this technically challenging group of patients. Several ventilator manufacturers have incorporated advanced algorithms that can reliably deliver the pre-set $\mathrm{V}_{\mathrm{T}}$ despite a large ETT leak. In one example, the ventilator continuously measures proximal flow and airway pressure, calculates the inspiratory and expiratory leak, and adjusts the inspiratory pressure based on an estimated volume delivered to the patient (Fig. 4). As volume-targeted strategies become more prevalent in the NICU, hopefully these new features will help provide better lung protection in the future. 


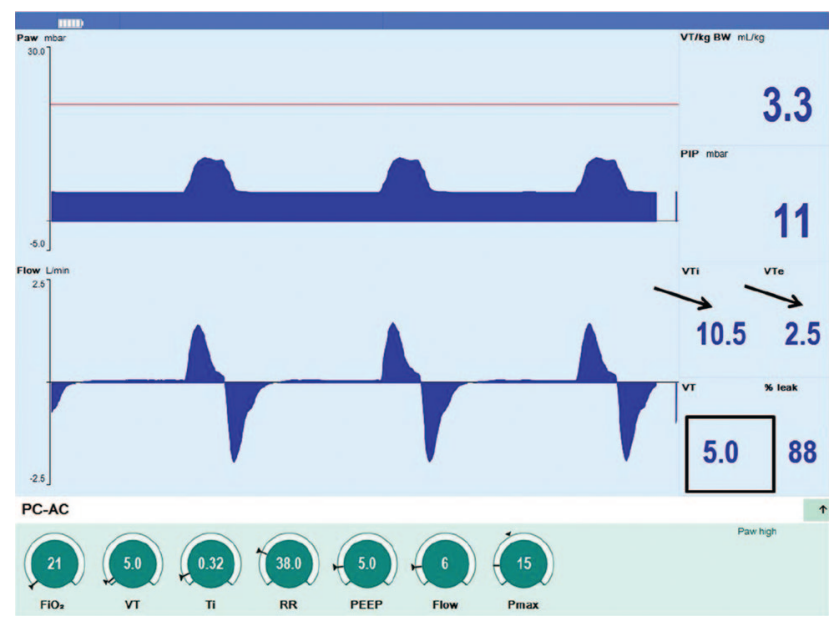

Fig. 4. Ventilator screen during testing of adaptive pressure control (volume-targeted) ventilation with the VN500 ventilator and a neonatal test lung. The set tidal volume $\left(\mathrm{V}_{\mathrm{T}}\right)$ was $5 \mathrm{~mL}$, and the simulated ETT leak was calculated at $88 \%$. The arrows point to the inhaled and exhaled $V_{T}$, measured at the proximal flow sensor. The $V_{T}$ value displayed in the box is the estimated volume delivered to the lung model after subtracting the leak volume. This is the volume measurement used by the adaptive pressure control algorithm. The $V_{T}$ measured in the lung model was identical to the estimated delivered $V_{\mathrm{T}}$ and the pre-set volume (data not shown).

\section{Lung-Protective Strategies}

Choosing the correct ventilation mode may enhance patient-ventilator synchrony, reduce air leaks, and decrease ventilation days. ${ }^{7,17-22}$ It may, however, be more important to choose the correct ventilation strategy, once the ventilation mode is chosen. There is evidence that optimization of the lung volume is key to lung protection, regardless of what ventilation mode is used. ${ }^{41,47,48}$ Neonatal animal studies indicated that reducing $\mathrm{V}_{\mathrm{T}}$ and using the appropriate PEEP can reduce VILI by avoiding volutrauma and atelectrauma. ${ }^{41,49,50}$ Open-lung ventilation uses a recruitment maneuver to open alveoli and optimize lung volume and avoids excessive lung inflation. There is evidence that open-lung ventilation with recruitment maneuvers can also reduce VILI and may be an important adjunct to limiting $\mathrm{V}_{\mathrm{T}}$ and applying adequate PEEP. ${ }^{51,52}$

In the NICU, recruitment maneuvers have been limited primarily to increasing mean airway pressure during HFV, and there is very little documentation of recruitment maneuvers being used during conventional ventilation. In adults treated for acute respiratory distress syndrome (ARDS), recruitment maneuvers during conventional ventilation showed promising results. ${ }^{53}$ Previous adult animal studies found that the lung can be recruited and kept open for the entire respiratory cycle. ${ }^{54}$ This is accomplished by short-term increases in inspiratory pressure and PEEP, which overcome the critical opening pressure and recruit collapsed alveoli.
Many have theorized that the major advantage of HFV over conventional ventilation is derived from the fact that this open-lung strategy uses higher mean airway pressure and that equal benefits may be observed if higher PEEP is used during conventional ventilation. In a laboratory study, 2 different open lung strategies were compared to conventional ventilation using lower PEEP settings. Neonatal piglets were randomly assigned to one of 3 groups, open lung conventional ventilation during conventional ventilation, open lung HFV, or traditional conventional ventilation. ${ }^{51}$ Arterial oxygenation and lung compliance was superior and alveolar protein infiltration were significantly reduced in the open-lung groups. Lung-injury scores were significantly higher in the conventional-ventilation group. In this neonatal piglet study, open-lung conventional ventilation was used with a respiratory rate of 120 breaths/min and a 1:1 inspiratory/expiratory ratio. PEEP was initially increased to $15 \mathrm{~cm} \mathrm{H}_{2} \mathrm{O}$, and inspiratory pressure was stepwise increased by $5 \mathrm{~cm} \mathrm{H}_{2} \mathrm{O}$ to open the lung. After the critical opening pressure was reached with the recruitment maneuver, inspiratory pressure and PEEP were simultaneously decreased in equal steps every 2-3 min, until $\mathrm{P}_{\mathrm{OO}_{2}}$ dropped below $450 \mathrm{~mm} \mathrm{Hg}$ (on 100\% oxygen), indicating increased intrapulmonary shunting due to alveolar collapse. The PEEP at that point was called the closing pressure. PEEP was then raised $2 \mathrm{~cm} \mathrm{H}_{2} \mathrm{O}$, and the inspiratory pressure was raised for about 10 seconds to the opening pressure to recruit the lung. The pressure amplitude was then set to keep the desired $\mathrm{P}_{\mathrm{aCO}_{2}}$. If there were signs of overdistention, such as rising $\mathrm{P}_{\mathrm{aCO}}$, decreasing $\mathrm{P}_{\mathrm{aO}}$, or decreasing blood pressure, then PEEP was decreased. Inspiratory pressure as high as $40 \mathrm{~cm} \mathrm{H}_{2} \mathrm{O}$ was required to overcome the critical opening pressure during conventional ventilation and HFV. The higher pressure was necessary to recruit the lung but did not appear to increase VILI, if only applied for a short period.

Additional studies are needed to determine how best to implement open-lung approaches with PEEP and HFV in premature neonates. Devices that appropriately monitor end-expiratory lung volume may also be useful to determine the appropriate mean airway pressure.

Permissive hypercapnia is a ventilation strategy that allows higher than normal $\mathrm{P}_{\mathrm{aCO}}$ during any form of ventilation, and may be a valuable tool for lung protection in premature neonates. Kraybill et al ${ }^{55}$ studied a multicenter, historical cohort of 235 infants with birth weights of $751-1,000 \mathrm{~g}$, to identify risk factors for chronic lung disease. Mechanically ventilated infants whose $\mathrm{P}_{a \mathrm{CO}_{2}}$ was $>50 \mathrm{~mm} \mathrm{Hg}$ at 48 hours had a lower risk of developing chronic lung disease. Permissive hypercapnia was investigated further in studies by Carlo et $\mathrm{al}^{56}$ and Mariani et al. ${ }^{57}$ Days of mechanical ventilation and mechanical ventilation support at 36 weeks were lower with permissive hypercapnia, but mortality and the BPD rate were not 
affected. In both the studies the $\mathrm{V}_{\mathrm{T}}$ target was $4 \mathrm{~mL} / \mathrm{kg}$, and permissive hypercapnia was accomplished primarily with ventilator rate adjustments. This is in contrast to the pivotal adult lung-protection study by ARDS Network that compared a low- $\mathrm{V}_{\mathrm{T}}$ strategy $(6 \mathrm{~mL} / \mathrm{kg})$ to a higher- $\mathrm{V}_{\mathrm{T}}$ strategy $(12 \mathrm{~mL} / \mathrm{kg}) .58$

There is very little clinical evidence to help determine what the $\mathrm{V}_{\mathrm{T}}$ target should be during volume-targeted ventilation. Lista et al ${ }^{59}$ sought to determine if a lower $\mathrm{V}_{\mathrm{T}}$ affects lung inflammation, which is an important risk factor for BPD. Thirty pre-term infants, 25-32 weeks gestation, with acute RDS were ventilated with $\mathrm{V}_{\mathrm{T}}$ of either $3 \mathrm{~mL} / \mathrm{kg}$ or $5 \mathrm{~mL} / \mathrm{kg}$. The $3-\mathrm{mL} / \mathrm{kg}$ group had a higher inflammatory response and a longer duration of ventilation than the $5-\mathrm{mL} / \mathrm{kg}$ group. Nassabeh-Montazami et al ${ }^{12}$ studied $\mathrm{V}_{\mathrm{T}}$ targets in low-birth-weight infants. They performed 344 paired observations of $\mathrm{V}_{\mathrm{T}}$ and arterial blood gas values in infants $<800 \mathrm{~g}$. The $\mathrm{V}_{\mathrm{T}}$ per kg required for normocapnia was inversely related to birth weight, which indicates that dead space from a proximal flow sensor may have an effect. In the infants $<500 \mathrm{~g}$ the mean $\mathrm{V}_{\mathrm{T}}$ was $5.9 \pm 0.4 \mathrm{~mL} / \mathrm{kg}$, and for those $>700 \mathrm{~g}$ the mean $\mathrm{V}_{\mathrm{T}}$ was $4.7 \pm 0.4 \mathrm{~mL} / \mathrm{kg}$. The absolute mean set and measured $\mathrm{V}_{\mathrm{T}}$ was almost equal to the estimated flow-sensor dead space plus the anatomical dead space while still maintaining normocapnia. Adequate ventilation occurred with $\mathrm{V}_{\mathrm{T}}$ at or below dead space. A follow-up study evaluated 828 paired arterial blood gas values and $\mathrm{V}_{\mathrm{T}}$ sets in babies $<800 \mathrm{~g}$ during the first 3 weeks of life. ${ }^{60}$ Despite permissive hypercapnia, the $\mathrm{V}_{\mathrm{T}}$ requirement rose with advancing postnatal age, from just over $5 \mathrm{~mL} / \mathrm{kg}$ on day 1 to over $6 \mathrm{~mL} / \mathrm{kg}$ by the end of 3 weeks. This effect is probably due to distention of the upper airways and increased alveolar dead space.

Neonatal lung injury can also occur when the infant's own breathing conflicts with the mechanical breaths from the ventilator. Patient-ventilator coordination can be affected by the set inspiratory time on the ventilator. Excessive inspiratory time can lead to active exhalation and other forms of asynchrony (Fig. 5) that may require more sedation and paralytic drugs. ${ }^{61}$ Though clinicians have new tools to assist in inspiratory-time optimization, it is not clear what the appropriate initial inspiratory time setting should be. A meta-analysis ${ }^{62}$ to determine whether a long or short inspiratory time affects the rates of air leak, BPD, and mortality, included 5 RCTs, with a total of 694 infants. A long inspiratory time $(>0.5 \mathrm{~s})$ was associated with a significant increase in air leak (typical RR $1.56,95 \%$ CI 1.25 to 1.94 , relative difference $0.13,95 \%$ CI 0.07 to 0.20 ), NNT $8,95 \%$ CI 5 to 14). There was no difference in the incidence of BPD. Long inspiratory time was also associated with higher mortality before hospital discharge, but that difference was of borderline statistical significance (typical RR $1.2695 \%$ CI 1.00 to 1.59 , relative dif-

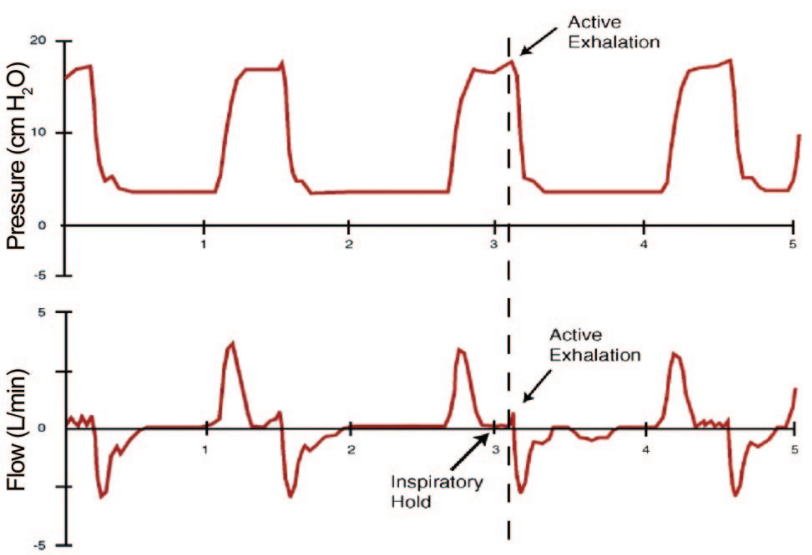

Fig. 5. Pressure and flow waveforms show that excessive inspiratory time causes active exhalation. The spikes at the end of each inspiration indicate that the patient is forcibly exhaling due to a prolonged inspiratory time. (Adapted from Reference 61, with permission.)

ference $0.07,95 \%$ CI 0.00 to 0.13 ). A limitation of that review is that the studies included were conducted prior to the introduction of antenatal steroids, surfactant-replacement therapy, and patient-triggered ventilation.

Many new approaches have been developed that provide valuable insight for managing premature neonates with RDS. Strategies differ considerably between institutions and between shifts in an NICU. Developing lungprotective, evidence-based ventilator management protocols is becoming very popular in the NICU setting.

\section{High-Frequency Ventilation}

HFV applies rapid respiratory rates of more than 150 breaths/min, with very small $\mathrm{V}_{\mathrm{T}}$ (less than the anatomic dead space), to provide adequate minute volume with a lower airway pressure. ${ }^{63}$ Some institutions employ HFV as a rescue therapy when conventional mechanical ventilation has failed, whereas others use it as a primary ventilation mode. There are 2 principal types of HFV: high-frequency oscillatory ventilation (HFOV), and highfrequency jet ventilation (HFJV).

HFOV uses a piston pump or vibrating diaphragm that produces a small $\mathrm{V}_{\mathrm{T}}$ around a set mean airway pressure. $\mathrm{A}$ bias flow of fresh gas clears carbon dioxide from the system. During HFOV, expiration is active rather than passive. As long as mean airway pressure is adequate to prevent airway collapse, active expiration may assist in reducing air trapping.

HFJV is used in conjunction with a conventional ventilator that delivers the PEEP, entrains gas, and provides intermittent sighs. A jet injector sends short pulses of gas directly into the trachea, which creates an area of negative pressure and entrains additional gas into the airway. Ex- 
piration is passive, and therefore HFJV may be used with lower mean airway pressure than HFOV without risk of airway collapse on exhalation, although insufficient expiratory time can still cause air trapping during HFJV.

In a Cochrane meta-analysis of 17 RCTs, with a total of 3,652 patients, there was no difference in 28-day mortality in premature neonates supported by conventional ventilation versus HFV. ${ }^{64}$ The effect of HFV and conventional ventilation on BPD was inconsistent across the studies, and there was a borderline significance favoring HFV. Some subgroups had significantly less BPD with HFV, but only when surfactant was not administered. Piston-driven oscillators, when conventional ventilation strategies were not lung-protective, when randomization occurred at 2-6 hours of age, and when the inspiratory/expiratory ratio was 1:2, were used for HFOV. The rate of retinopathy of prematurity was lower, overall, and pulmonary air leaks were more frequent in the HFOV group. The rates of grade 3 or 4 intraventricular hemorrhage and periventricular leukomalacia were higher in the HFOV groups that used a high-volume strategy. One trial found an adverse effect on long- term neurodevelopment with HFOV, but the other 5 trials that reported this outcome did not. It is important to note that several different forms of HFV were used, routine monitoring of arterial blood gases were not performed in all patients, and many of the neonates were managed with lower-mean-airway-pressure approaches during HFV. These factors may account for many of the observed differences.

In a Cochrane meta-analysis of HFOV versus conventional ventilation for near-term and term infants with severe pulmonary dysfunction, 2 trials met the review criteria. ${ }^{65}$ One involved the elective use of HFOV and randomized 118 infants. The other used HFOV as a rescue therapy in 81 infants. Neither trial found lower mortality at 28 days. There was no difference in air leak, BPD, or intracranial injury. In the elective HFOV study there was no difference in ventilator days or hospital days. In the rescue HFOV study there was no difference in the need for extracorporeal membrane oxygenation. Based on the prior review, it was stated: "There is no clear evidence that elective HFOV offers important advantages over conventional ventilation when used as the initial ventilation strategy to treat pre-term infants with acute pulmonary dysfunction." 65

In 2010 a systematic review and meta-analysis used individual patient data from $12 \operatorname{RCTs}(n=3,229$ patients) to compare outcomes in pre-term infants who received HFOV (higher mean airway pressure) versus conventional ventilation. ${ }^{66}$ There were no differences in $\mathrm{BPD}$, mortality, or neurological insult. However, when randomization occurred earlier (within $4 \mathrm{~h}$ ), HFOV was associated with less death and less chronic lung disease $(P=.01)$, and with fewer air leaks, fewer surgical ligations of patent ductus arteriosus, and less retinopathy of prematurity ( $\geq$ stage 2 ).

For infants with pulmonary interstitial emphysema, HFJV is more effective than high-rate conventional ventilation, and associated with lower mortality in the smallest infants and a quicker time to resolution. ${ }^{67}$ In a 1998 metaanalysis $^{68}$ of elective HFJV versus conventional ventilation, HFJV was associated with less BPD at 36 weeks postmenstrual age in survivors (RR $0.58,95 \%$ CI 0.34 to 0.98 , relative difference $-0.138,95 \%$ CI -0.268 to -0.007 ), NNT 7 (95\% CI 4 to 90). The overall analysis found that elective HFJV benefited pulmonary outcomes. Many of the trials reviewed compared HFV only to pressure control ventilation. Future trials of open-lung HFV versus conventional ventilation should include volumetargeted ventilation modes with small $\mathrm{V}_{\mathrm{T}}(4-6 \mathrm{~mL} / \mathrm{kg})$, rapid respiratory rate, short inspiratory time, and permissive hypercapnia.

\section{Closed-Loop $\mathrm{F}_{\mathrm{IO}_{2}}$ Control}

Premature infants often need supplemental oxygen for extended periods. Retinopathy of prematurity can be caused by excessive $\mathrm{F}_{\mathrm{IO}_{2}}$, and BPD has been attributed partly to high $\mathrm{F}_{\mathrm{IO}_{2}}{ }^{69}$ The optimal oxygen saturation is still under investigation. Manual control of $\mathrm{F}_{\mathrm{IO}_{2}}$ during mechanical ventilation can be difficult and time-consuming. Automated (closed-loop) regulation of $\mathrm{F}_{\mathrm{IO}_{2}}$ is a new concept that is awaiting FDA approval for use in one neonatal ventilator. The clinician sets the target $\mathrm{S}_{\mathrm{pO}_{2}}$ range on the ventilator, and the ventilator titrates $\mathrm{F}_{\mathrm{IO}_{2}}$ based on the $\mathrm{S}_{\mathrm{pO}_{2}}$.

In a study of 16 pre-term infants $(24.9 \pm 1.4$ weeks $)$ with frequent hypoxemia episodes, the percent of time within the target $\mathrm{S}_{\mathrm{pO}_{2}}$ range was greater with automated $\mathrm{F}_{\mathrm{IO}_{2}}$ control $(58 \pm 10 \%$ vs $42 \pm 9 \%, P<.001) .{ }^{70}$ Automated oxygen control also reduced hyperoxemia and $\mathrm{F}_{\mathrm{IO}_{2}}$. Theoretically, automated $\mathrm{F}_{\mathrm{IO}_{2}}$ control could decrease the frequency of hypoxic and hyperoxic episodes in infants receiving mechanical ventilation, and reduce clinician time and the risk of morbidities associated with supplemental oxygen (retinopathy of prematurity and BPD). Closedloop control is a promising approach, and may be available in the near future.

\section{Summary}

Although the trend in the neonatal NICU is to use NIV whenever possible, invasive ventilation is often necessary in pre-term neonates with lung disease. Many different ventilation modes and ventilation strategies are available to optimize mechanical ventilation and prevent VILI. Patient-triggered ventilation is favored over machinetriggered forms of invasive ventilation for improving gas exchange and patient-ventilator interaction. However, no 
studies have shown that patient-triggered ventilation improves mortality or morbidity in premature neonates. A promising new form of patient-triggered ventilation, neurally adjusted ventilatory assist, was recently FDA approved for invasive and noninvasive ventilation. Clinical trials are underway to evaluate NAVA outcomes in neonates. New evidence suggests that volume-targeted ventilation modes may be more beneficial in providing better lung protection than traditional pressure control modes. A number of volume-targeted modes that provide accurate $\mathrm{V}_{\mathrm{T}}$ delivery in the face of a large ETT leak have recently been introduced to the clinical setting. There is ongoing debate about whether neonates should be managed invasively with HFV or conventional ventilation at birth. The majority of clinical trials performed to date have compared HFV to pressure control modes. Future trials with neonates should compare HFV to conventional ventilation with volume-targeted modes and permissive hypercapnia. Over the past decade, many new promising approaches to lungprotective ventilation strategies have evolved. The key to protecting the neonatal lung during mechanical ventilation is to optimize lung volume and limit excessive lung expansion, with appropriate PEEP, short inspiratory time, small $\mathrm{V}_{\mathrm{T}}(4-6 \mathrm{~mL} / \mathrm{kg})$, and permissive hypercapnia.

The future of neonatal invasive ventilation appears promising. New technologies are being developed daily and are likely to improve the care of these delicate patients. Management protocols are being devised using only the best available experimental findings. Widespread acceptance of new devices and approaches will continue to rely on data obtained from well designed bench, animal, and clinical studies to better understand their role in the NICU environment.

\section{REFERENCES}

1. Singh GK, Yu SM. Infant mortality in the United States: trends, differentials, and projections 1950 through 2010. Am J Public Health 1995;85(7):957-964.

2. Heron M, Sutton PD, Xu J, Ventura SJ, Strobino DM, Guyer B. Annual summary of vital statistics: 2007. Pediatrics 2010;125(1):415.

3. Avery ME, Tooley WH, Keller JB, Hurd SS, Bryan MH, Cotton RB et al. Is chronic lung disease in low birth weight infants preventable? A survey of eight centers. Pediatrics 1987;79(1):26-30.

4. Ramanathan R, Sadesai S. Lung protective ventilatory strategies in very low birth weight infants. J Perinatol 2008;28(Suppl 1): S41-S46.

5. SUPPORT study group: Finer NN, Carlo WA, Walsh MC, Rich W, Gantz MG, Laptook AR, et al. Early CPAP versus surfactant in extremely preterm infants. N Engl J Med 2010;362(21):1970-1979.

6. Wilson BG, Cheifetz IM, Meliones JN. Optimizing mechanical ventilation in infants and children. Yorba Linda, CA: CareFusion. 1995.

7. Donn SM, Sinha SK. Can mechanical ventilation strategies reduce chronic lung disease? Semin Neonatol 2003;8(6):441-448.
8. Cools F, Offringa M. Neuromuscular paralysis for newborn infants receiving mechanical ventilation. Cochrane Database Syst Rev 2005; (2):CD002773.

9. Dimitriou G, Greenough A, Laubscher B, Yamguchi N. Comparison of airway pressure triggered and airflow-triggered ventilation in very immature infants. Acta Paediatr 1998;87(12):1256-1260.

10. Dimitriou G, Greenough A, Cherian S. Comparison of airway pressure and airflow triggering systems using a single type of neonatal ventilator. Acta Paediatr 2001;90(4):445-447.

11. Keszler M. State of the art in conventional mechanical ventilation. J Perinatol 2009;29(4):262-275.

12. Nassabeh-Montazami S, Abubakar KM, Kezler M. The impact of instrumental dead-space in volume-targeted ventilation of the extremely low birth weight infant. Pediatr Pulmonol 2009;44(2):128133.

13. Bernstein G, Heldt GP, Mannino FL. Increased and more consistent tidal volumes during synchronized intermittent mandatory ventilation in newborn infants. Am J Respir Crit Care Med 1994;150(5 Pt 1):1444-1448.

14. Cleary JP, Bernstein G, Mannino FL, Heldt GP. Improved oxygenation during synchronized intermittent mandatory ventilation in neonates with respiratory distress syndrome: a randomized, crossover study. J Pediatr 1995;126(3):407-411.

15. Jarreau PH, Moriette G, Mussat P, Mariette C, Mohanna A, Harf A, Lorino H. Patient-triggered ventilation decreases the work of breathing in neonates. Am J Respir Crit Care Med 1996;153(3):1176-1181.

16. Smith KM, Wahlig TM, Bing DR, Georgieff MK, Boros SJ, Mammel MC. Lower respiratory rates without decreases in oxygen consumption during neonatal synchronized intermittent mandatory ventilation. Intensive Care Med 1997;23(4):463-468.

17. Hummler H, Gerhardt T, Gonzalez A, Claure N, Eberett R, Bancalari E. Influence of different methods of synchronized mechanical ventilation on ventilation, gas exchange, patient effort, and blood pressure fluctuations in premature neonates. Pediatr Pulmonol 1996; 22(5):305-313.

18. Mrozek JD, Bendel-Stenzel EM, Meyers PA Bing DR, Connett JE, Mammel MC. Randomized controlled trial of volume-targeted synchronized ventilation and conventional intermittent mandatory ventilation following initial exogenous surfactant therapy. Pediatr Pulmonol 2000;29(1):11-18.

19. Dimitriou G, Greenough A, Griffen F, Chan V. Synchronized intermittent mandatory ventilation modes compared with patient-triggered ventilation during weaning. Arch Dis Child Fetal Neonatal Ed 1995; 72(3):F188-F190.

20. Chan V, Greenough A. Comparison of weaning by patient triggered ventilation or synchronous intermittent mandatory ventilation. Acta Paediatr 1994;83(3):335-337.

21. Greenough A, Dimitriou G, Prendergast M, Milner AD. Synchronized mechanical ventilation for respiratory support in newborn infants. Cochrane Database Syst Rev 2008;(1):CD000456.

22. Sarkar S, Donn SM. In support of pressure support. Clin Perinatol 2007;34(1):117-128.

23. Poets CF, Rau GA, Neuber RK, Gappa M, Seidenberg J. Determinants of lung volume in spontaneously breathing preterm infants. Am J Respir Crit Care Med 1997;155(2):649-653.

24. Schulzke SM, Pillow J, Ewald B, Patole SK. Flow-cycled versus time-cycled synchronized ventilation for neonates. Cochrane Database Syst Rev 2010;(7):CD008246.

25. Nicks JJ, Becker MA, Donn SM. Ventilatory management casebook. Bronchopulmonary dysplasia. Response to pressure support ventilation J Perinatol 1994;14(6):495-497.

26. Nafday SM, Green RS, lin J, Brion LP, Ochshorn I, Holzman IR. Is there an advantage of fusing pressure support ventilation with volume guarantee in the management of premature infants with respi- 


\section{Mechanical Ventilation of the Premature Neonate}

ratory distress syndrome? A pilot study. J Perinatol 2005;25(3):193197.

27. Olsen SL, Thibeault DW, Truog WE. Crossover trial comparing pressure support with synchronized intermittent mandatory ventilation. J Perinatol 2002;22(6):461-466.

28. Gupta S, Sinha SK, Donn SM. The effect of two levels of pressure support ventilation on tidal volume delivery and minute ventilation in preterm infants. Arch Dis Child Fetal Neonatal Ed 2009;94(2): F80-F83.

29. Reyes ZC, Claure N, Tauscher MK, D'Ugard C, Vanbuskirk S, Bancalari E. Randomized, controlled trial comparing synchronized intermittent mandatory ventilation and synchronized intermittent mandatory ventilation plus pressure support in preterm infants. Pediatrics 2006;118(4):1409-1417.

30. Kapasi M, Fujino Y, Kirmse M, Catlin EA, Kacmarek RM. Effort and work of breathing in neonates during assisted patient-triggered ventilation. Pediatr Crit Care Med 2001;2(1):9-16.

31. Sinderby C, Navalesi P, Beck J, Skrobik Y, Comtois N, Friberg S, et al. Neural control of mechanical ventilation in respiratory failure. Nature Med 1999;5(12):1433-1436.

32. Kacmarek RM. Proportional assist ventilation and neurally adjusted ventilatory assist. Respir Care 2011;56(2):140-148; discussion 149152.

33. Beck J, Reilly M, Grasselli G, Mirabella L, Slutsky AS, Dunn MS, Sinderby C. Patient-ventilator interaction during neurally adjusted ventilatory assist in low birth weight infants. Pediatr Res 2009;65(6): 663-668.

34. Breatnach C, Conlon NP, Stack M, Healy M, O'Hare BP. A prospective crossover comparison of neurally adjusted ventilatory assist and pressure support ventilation in a pediatric and neonatal intensive care unit population. Pediatr Crit Care Med 2010;11(1):7-11.

35. Walsh BK, Craig N, Betit P, Thompson JE, Arnold JH. Respiratory distress associated with inadequate mechanical ventilator flow response in a neonate with congenital diaphragmatic hernia. Respir Care 2010;55(3):342-345.

36. Baraldi E, Filippone M. Chronic lung disease after premature birth. N Engl J Med 2007:357(19):1946-1955.

37. Wiswell TE, Graziani LJ, Kornhauser MS, Stanley C, Merton DA, McKee L, Spitzer AR. Effects of hypocarbia on the development of cystic periventricular leukomalacia in premature infants treated with high-frequency jet ventilation. Pediatrics 1996;98(5):918-924.

38. Miyamoto E, Tomimoto H, Nakao Si S, Wakita H, Akiguchi I, Miyamoto K, Shingu K. Caudoputamen is damaged by hypocapnia during mechanical ventilation in a rat model of chronic cerebral hypoperfusion. Stroke 2001;32(12):2920-2925.

39. Kaiser JR, Gauss CH, Pont MM, Williams DK. Hypercapnia during the first 3 days of life is associated with severe intraventricular hemorrhage in very-low birth-weight infants. J Perinatol 2006;26(5): 279-285.

40. Fabres J, Carlo WA, Phillips V, Howard G, Ambalavanan N. Both extremes of arterial carbon dioxide pressure and the magnitude of fluctuations in arterial carbon dioxide pressure are associated with severe intraventricular hemorrhage in preterm infants. Pediatrics 2007;119(2):299-305

41. Muscedere JG, Mullen JB, Gan K, Slutsky AS. Tidal ventilation at low airway pressures can augment lung injury. Am J Respir Crit Care Med 1994;149(5):1327-1334.

42. Sinha SK, Donn SM, Gavey J, McCarty M. Randomized trial of volume controlled versus time cycled, pressure limited ventilation in preterm infants with respiratory distress. Arch Dis Child Fetal Neonatal Ed 1997;77(3):F202-F205.

43. Wheeler K, Klingenberg C, McCallion N, Morley CJ, Davis PG. Volume-targeted versus pressure-limited ventilation in the neonate. Cochrane Database Syst Rev 2010;(11):CD003666.
44. van Kaam AH, Rimensberger PC, Borensztajn D, De Jaegere AP; Neovent Study Group. Ventilation practices in the neonatal intensive care unit: a cross-sectional study. J Pediatr 2010;157(5):767-771.

45. Cannon ML, Cornell J, Tripp-Hamel DS, Gentile MA, Hubble CL, Meliones JN, Cheifetz IM. Tidal volumes for ventilated infants should be determined with a pneumotachometer placed at the endotracheal tube. Am J Respir Crit Care Med 2000;162(6):2109-2112.

46. Heulitt MJ, Holt SJ, Thurman TL, Hall RA, Jo CH Simpson P. Reliability of measured tidal volume in mechanically ventilated young pigs with normal lungs. Intensive Care Med 2005;31(9):1255-1261.

47. Dreyfuss D, Saumon G. Barotrauma is volutrauma but which volume is the one responsible? Intensive Care Med 1992;18(3):139-141.

48. Ricard, JD, Dreyfuss, D, Saumon G. Ventilator-induced lung injury. Eur Respir J Suppl 2003;(42):2S-9S.

49. Wada K, Jobe AH, Ikegami M. Tidal volume effects on treatment responses with the initiation of ventilation in preterm lambs. J Appl Physio 1997;83(4):1054-1061.

50. Tremblay L, Valenza F, Ribeiro SP, Li J, Slutsky AS. Injurious ventilatory strategies increase cytokines and c-fos m-RNA expression in an isolated rat lung model. J Clin Invest 1997;99(5):944-952.

51. van Kaam AH, de Jaegere A, Haitsma JJ, Van Aalderen WM, Kok JH, Lachmann B. Positive pressure ventilation with the open lung concept optimizes gas exchange and reduces ventilator induced lung injury in newborn piglets Pediatr Res 2003;53(2):245-253.

52. Rimensberger PC, Cox PN, Frndova H, Bryan AC. The open lung during small tidal volume ventilation: concepts of recruitment and "optimal" positive end-expiratory pressure. Crit Care Med 1999; 27(9):1946-152.

53. Amato MB, Barbas CS, Medeiros DM, Magaldi RB, Schettino GP, Lorenzi-Fiho $\mathrm{G}$ et al. Effect of a protective-ventilation strategy on mortality in the acute respiratory distress syndrome. N Engl J Med 1998;338(6):347-354.

54. Lachmann B, Jonson B, Lindroth M, Robertson B. Modes of ventilation in severe respiratory distress syndrome. Lung function and morphology in rabbits after wash-out of alveolar surfactant. Crit Care Med 1982;10(11):724-732.

55. Kraybill EN, Runyun DK, Bose CL, Khan JH. Risk factors for chronic lung disease in infants with birth weights of 751 to 1000 grams. J Pediatr 1989;115(1):115-120.

56. Carlo WA, Stark AR, Wright LL, Tyson JE, Papile LA, Shankaran S et al. Minimal ventilation to prevent bronchopulmonary dysplasia in extremely- low-birth-weight infants. J Pediatr 2002;141(3):370-374.

57. Mariani G, Cifuentes J, Carlo WA. Randomized trial of permissive hypercapnia in preterm infants. Pediatrics 1999;104(5 Pt 1):1082-1088.

58. The Acute Respiratory Distress Syndrome Network. Ventilation with lower tidal volumes as compared with traditional tidal volumes for acute lung injury and the acute respiratory distress syndrome. $\mathrm{N}$ Engl J Med 2000;342(18):1301-1308.

59. Lista G, Catoldi F, Fontana P, Reali R, Reggiani A, Bianchi S, Comagnoni G. Lung inflammation in preterm infants with respiratory distress syndrome: effects of ventilation with different tidal volumes. Pediatr Pulmonol 2006;41(4):357-363.

60. Keszler M, Nassabeh-Montazami S, Abubakar K. Evolution of tidal volume requirement during the first 3 weeks of life in infants in infants $<800 \mathrm{~g}$ ventilated with volume guarantee. Arch Dis Child Fetal Neonatal Ed. 2009;94(4):F279-F282.

61. Waugh JB, Harwood R, Deshpande VM. Rapid interpretation of ventilator waveforms. 2nd edition. Upper Saddle River, New Jersey: Pearson/Prentice Hall; 2007:122.

62. Kamlin COF, Davis PG. Long versus short inspiratory times in neonates receiving mechanical ventilation. Cochrane Database Syst Rev 2004;(4):CD004503.

63. Brown M, Mason S. Neonatal and pediatric respiratory care. In: Hess D, MacIntyre N, Mishoe S, Galvin W, Adams A, editors. Respiratory 
care: principles and practice, 2nd edition. Sudbury, MA: Jones \& Bartlett; 2011:521-548.

64. Cools F, Henderson-Smart DJ, Offringa M, Askie LM. Elective high frequency oscillatory ventilation versus conventional ventilation for acute pulmonary dysfunction in preterm infants. Cochrane Database Syst Rev 2009;(3):CD000104.

65. Henderson-Smart DJ, De Paoli AG, Clark RH, Bhuta T. High frequency oscillatory ventilation versus conventional ventilation for infants with severe pulmonary dysfunction born at or near term. Cochrane Database Syst Rev 2009;(3):CD002974.

66. Cools F, Askie LM, Offringa M, Asselin JM, Calvert SA, Courtney SE, Dani $\mathrm{C}$, et al. Elective high-frequency oscillatory versus conventional ventilation in preterm infants: a systematic review and meta-analysis of individual patients' data. Lancet 2010;375(9731):2082-2091.
67. Kezler M, Donn SM, Bucciarelli RI, Alverson DC, Hart M, Lunyong $\mathrm{V}$, Modanlou HD et al. Multicenter controlled trial comparing highfrequency jet ventilation and conventional ventilation in newborn infants with pulmonary interstitial emphysema. J Pediatr 1991;119(1 Pt 1):85-93.

68. Bhuta T, Henderson-Smart DJ. Elective high frequency jet ventilation versus conventional ventilation for respiratory distress syndrome in preterm infants. Cochrane Database Syst Rev 2000;(2):CD000328.

69. Northway WH, Rosen RC, Porter DY. Pulmonary disease following respiratory therapy of hyaline membrane disease. Bronchopulmonary dysplasia. N Engl J Med 1967;276(7):357-368.

70. Claure N, D'ugard C, Bancalari E. Automated adjustment of inspired oxygen in preterm infants with frequent fluctuations in oxygenation: a pilot clinical trial. J Pediatr 2009;155(5):640-645.

\section{Discussion}

Rogers:* As a point of disclosure, I'm the high-frequency product manager for CareFusion. It's important to realize that the meta-analysis that compared HFOV to conventional ventilation looked at all the RCTs, which included a couple of trials done very early in the history of HFV, primarily the HiFO Trial $^{1}$ and the UKOS trial, ${ }^{2}$ both of which had serious flaws, including lack of a strict protocol and clinical trial oversight, and disparate high-frequency devices. We must look at the type of high-frequency device, rather than combining all highfrequency devices. In the recent Cochrane meta-analysis, ${ }^{3}$ for pistondriven high-frequency ventilators the incidence of intraventricular hemorrhage and retinopathy of prematurity were lower for piston HFOV than for conventional ventilation.

Regarding future studies, it's much easier to justify putting a patient on HFOV, and in the pediatric realm using a mean airway pressure of 25 or $30 \mathrm{~cm} \mathrm{H}_{2} \mathrm{O}$, than on conventional ventilation at a similar PEEP. How many times have you seen a PEEP of 20 or $30 \mathrm{~cm} \mathrm{H}_{2} \mathrm{O}$ in neonatal or pediatric patients? Having a more comparative group between conventional and highfrequency is good for getting more

\footnotetext{
* Mark Rogers RRT, CareFusion, San Diego, California.
}

useful data. It boils down to the person driving the ventilator. I would much rather have Rich [Branson] driving a conventional ventilator than someone who's never seen a highfrequency device driving it. Just intuitively, I think high-frequency does yield better results. Alison Froese pointed out that one good thing HFV has done is show us how to use conventional ventilators better.

1. Clark RH, Gerstmann DR, Null DM Jr, deLemos RA. Prospective randomized comparison of high-frequency oscillatory and conventional ventilation in respiratory distress syndrome. Pediatrics 1992;89(1):5-12.

2. Johnson AH, Peacock JL, Greenough A, Marlow N, Limb ES, Marston L, Calvert SA; United Kingdom Oscillation Study Group. High-frequency oscillatory ventilation for the prevention of chronic lung disease of prematurity. N Engl J Med 2002; 347(9):633-642.

3. Cools F, Henderson-Smart DJ, Offringa M, Askie LM. Elective high-frequency oscillatory ventilation versus conventional ventilation for acute pulmonary dysfunction in pre-term infants. Cochrane Database Syst Rev 2009;(3):CD000104.

Brown: I agree. I spent many years using high-frequency in pediatric and neonatal ICUs. If it wasn't working for us, I don't think we'd keep using it, so there's something there, but sometimes it's hard to find in the studies. As for whether we can design the right study, sometimes I think we can't. It's difficult when all the studies are combined like that to really see the facts about the individual devices.
Walsh: You didn't mention anything about extubation readiness testing or what pressure you think is appropriate to extubate from.

Brown: It depends what part of the country you're from. I think there's an east-coast/west-coast thing going on, which I see when I collaborate with people further east than me. I don't think anybody really knows the right answer. My experience is that the sooner you try, the more likely you'll get them off faster, and I think the adult evidence bears that out, and that's how we ended up with spontaneous breathing trials, which we can't do in the NICU, but just force people to come off the ventilator sooner. The east-coast numbers are a lot higher than the west-coast numbers. On the west coast they'll go down to a ventilator rate of 12 breaths a minute. As for pressure, I think it should be tidalvolume-based and what the baby can do on his own, and come up with a combination with the ventilator.

Walsh: I'm not sure that the NICU doesn't have it right. They're not doing all these fancy ventilation modes, because it probably doesn't matter. It's something we've continuously explored in the pediatric and adult world, but I wonder if they're actually more evidence-based than the rest of the pediatric ICUs.

Brown: I kind of agree with you. It's funny that, if you're around long 
enough, everything comes back around, I distinctly remember standing at the bedside in the pediatric ICU trying to explain to an intensivist why he needed to learn pressure-support ventilation and he said, I've never needed it before, so why do I need it now? It was a good argument and maybe we don't need those modes at all. Though I have seen good things with babies with really bad chronic lung disease on a mode such as adaptive support ventilation; I've seen their comfort improve dramatically and seen them get off the ventilator when they couldn't get off it before. So maybe there's some use for some of those things. I don't want to throw them all out. I agree with you that we're going back to some simpler things.

Walsh: But you said that continuous mandatory ventilation produces less WOB. Maybe you' re right, maybe it's causing more lung damage because we're over-supporting them when we shouldn't be.

Brown: I agree. I kind of have two separate goals: one is to decrease WOB, and the other one is to not cause more damage. Maybe sometimes those are in competition with each other.

Wiswell: I'll be the contrarian. You've expressed bewilderment about why we haven't come around in neonatology. I've been doing this for over 30 years. The biggest change in ventilation came about 40 years ago with the advent of IMV and the first BabyBird ventilator. We have yet to show that anything else is better. I was involved in San Antonio in the mid1980s ventilating premature baboons, and in the first human baby trials, and I've been involved in high-frequency trials including the one by Courtney et al a couple years ago, which found maybe it's a little bit better. ${ }^{1}$

I think it makes sense to use patient-triggered and volume-limited ventilation, but I'm a realist. We haven't even shown that simple things like patient-ventilator synchrony make a difference. We have to look at what are the most clinically relevant end points? For me as a neonatologist, it's mortality and chronic lung disease. We haven't shown any differences.

Some trials have found that maybe we're a little bit better on duration of ventilation, and maybe fewer air leaks, but in general we're not doing better. In our National Institute of Child Health and Human Development sponsored neonatal network, which does a lot of our clinical trials, clearly the site that has the lowest BPD rate is Columbia [University Medical Center], in New York, and their main method of mechanical ventilation is IMV, 1970s-style ventilation.

1. Courtney SE, Durand DJ, Asselin JM, Hudak ML, Aschner JL, Shoemaker CT; Neonatal Ventilation Study Group. High frequency oscillatory ventilation versus conventional mechanical ventilation for very-low-birth-weight infants. N Engl J Med 2002;347(9):643-652.

Brown: I agree, and I pointed out that there were no BPD or mortality differences. Patient-triggered volumetargeted ventilation makes sense. There is evidence that volume targeting is safer. I'm not wholeheartedly embracing anything beyond that, but I do think it's interesting that we haven't even embraced those things in some places. Columbia is special because the physician in that unit is so special, and that expertise makes a difference. Doing what you do best is the most important thing, obviously.

DiBlasi: Perhaps it's not that we should be doing the right thing, but that we should be doing the same thing, because we don't really know what is the right thing to do. Rather than using four different ventilation modes with two different ventilators and switching between the two, I think that following a standardized ventilation management protocol might change outcomes.
I found it very interesting that in that meta-analysis table you showed, of outcomes in infants supported with volume-targeted versus pressure control ventilation, that the majority of the babies supported with volume-targeted ventilation received volumecontrol, and not one of the new-fangled dual-control modes. My concern is that the technology is changing so rapidly that data obtained from older studies that used older technologies do not extrapolate to the newer modes.

Last week one manufacturer told me that they were servo-controlling inspiratory pressure based on exhaled $\mathrm{V}_{\mathrm{T}}$, and the next week another ventilator manufacturer tells me that they're trying to target $\mathrm{V}_{\mathrm{T}}$ based on a theoretical delivered $\mathrm{V}_{\mathrm{T}}$ with a $90 \%$ ETT leak. This is great technology but how can we all keep up and who will fund a large enough RCT to determine if they're better than what we're using now?

Brown: No, if we've not gotten anywhere near that in the adult world, we're never going to get near it in the neonatal world. I'm not even advocating that we do. I think it's nice to have some things available that might work for particularly difficult babies, but I don't think it's what we need for most of the babies most of the time. When I was reading the studies, I thought it was very interesting that a lot of them used volume-controlled square-waveform flow versus decelerating flow.

Cheifetz: You discussed various ventilation strategies, including the open-lung approach. For the purposes of your presentation, you maintained your discussion of mode and strategy/ approach as separate entities. But what is most important? Does the specific ventilator mode really matter? Or is the approach/strategy the key issue, regardless of the mode? What are the outcome data to support mode versus ventilation strategy in neonates? In pediatrics there are no data to support 
one mode over another in terms of outcome in acute-lung-injury and ARDS patients. In my opinion the key is an open-lung, low- $\mathrm{V}_{\mathrm{T}}$ strategy, regardless of the specific ventilation mode.

Brown: Strategy. The only evidence we have is strategy. Open lung is important, and we need more evidence in the NICU, but that's probably some of the high-frequency success. That's why I think high-frequency ventilation often does better. There's some evidence that volume-targeting is important. I kind of "beat up on" the fact that we're still using pressure ventilation in the NICU, because I think volume-targeting is important and the evidence is there. I see volumes all over the place in the NICU. It drives me crazy to see over $25 \mathrm{~mL}$ being used in a 4-kg baby.

DiBlasi: Is it the machine or the baby?

Brown: It's the machine.

Myers: Regarding volume-targeting I want to restate the question: is it the baby or is it the technology? Babies have such rapidly changing lung compliance with what we know best, which is RDS, and it's all over the board. I'm not convinced the technology is there yet. With a 400 or 500 gram newborn, how do you target 3 or $5 \mathrm{~mL} /$ $\mathrm{kg}$ ? That's about 1.5-2 mL, and I'm not sure the ventilation technology is that accurate. I'm not sure it's accurate below 3 or even $5 \mathrm{~mL}$ with the technology we have, or if we can measure it. And there's a lot of variability. Rather than propagating more modes, I think we need to study in detail what we have now, and what we're actually capable of doing. With volumetargeting I see $\mathrm{CO}_{2}$ run all over the place, despite no changes in settings.

Brown: I agree, I don't think modes are the answer at all. We definitely need to do better with what we have now. We still have to control the pressure; I'm certainly not advocating that we simply target the volume and let the machine run away with it and trust that completely. I don't advocate that at all.

This article is approved for Continuing Respiratory Care Education credit. For information and to obtain your CRCE

(free to AARC members) visit

www.RCJournal.com

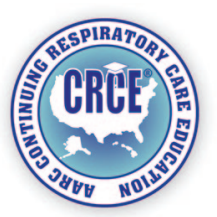

